\title{
International Journal of Doctoral Studies
}

An Official Publication

of the Informing Science Institute

InformingScience.org

IJDS.org

Volume 13, 2018

\section{WHERE'S THE DATA? USING DATA CONVINCINGLY IN TRANSDISCIPLINARY DOCTORAL RESEARCH}

\begin{tabular}{|c|c|c|}
\hline Jane Palmer* & $\begin{array}{l}\text { University of Southern Queensland, } \\
\text { Toowoomba, Australia }\end{array}$ & Jane.Palmer@usq.edu.au \\
\hline Dena Fam & $\begin{array}{l}\text { University of Technology Sydney, } \\
\text { Sydney, Australia }\end{array}$ & Dena.Fam@uts.edu.au \\
\hline Tanzi Smith & $\begin{array}{l}\text { University of Technology Sydney, } \\
\text { Sydney, Australia }\end{array}$ & Tanzi.Smith@uts.edu.au \\
\hline Jennifer Kent & $\begin{array}{l}\text { University of Technology Sydney, } \\
\text { Sydney, Australia }\end{array}$ & Lennifer.Kent@uts.edu.au \\
\hline
\end{tabular}

\section{ABSTRACT}

Aim/Purpose

The aim of this paper is to identify some of the issues in writing a transdisciplinary doctoral thesis and to develop strategies for addressing them, particularly focusing on the presentation of data and data analysis. The paper, based on the authors' own experience, offers guidance to, and invites further comment from, transdisciplinary doctoral candidates, their supervisors and their examiners, as well as the broader field of interdisciplinary and multidisciplinary researchers.

Background The paper uses the authors' experience of writing four very different transdisciplinary doctoral theses to examine the diverse responses received from examiners and what this means for the thesis writing process. The theses and examiners' reports span an array of disciplinary and transdisciplinary epistemologies, ontologies, and world views.

Methodology

A preliminary review of the examiners' reports revealed a common concern with the definition of 'data' and with 'data analysis'. The examiners' reports were then more formally coded and thematized. These themes were then used to reflect critically on the four theses, within a broad interpretive framework based on the idea of writing 'convincingly', and in light of current literature on the meaning of 'data' and the idea and aims of transdisciplinarity.

Contribution The paper offers specific strategies for doctoral candidates, their supervisors, and examiners in working with the burgeoning number of doctoral research projects that are now taking place in the transdisciplinary space.

Accepted by Editor Peter John Sandiford | Received: October 30, 2017| Revised: January 15, 2018 | Accepted: January 23, 2018.

Cite as: Palmer, J., Fam, D., Smith, T., \& Kent, J. (2018). Where's the data? Using data convincingly in transdisciplinary doctoral research. International Journal of Doctoral Studies, 13, 9-29. https://doi.org/10.28945/3941

(CC BY-NC 4.0) This article is licensed to you under a Creative Commons Attribution-NonCommercial 4.0 International License. When you copy and redistribute this paper in full or in part, you need to provide proper attribution to it to ensure that others can later locate this work (and to ensure that others do not accuse you of plagiarism). You may (and we encourage you to) adapt, remix, transform, and build upon the material for any non-commercial purposes. This license does not permit you to use this material for commercial purposes. 
Findings

Recommendations for Practitioners

Recommendations for Researchers

Impact on Society

Future Research

Keywords
Doctoral candidates engaged in transdisciplinary research need to define what they mean by data and make data visible in their research, be creative in their conceptions of data and in how they communicate this to examiners, specify the quality criteria against which they wish their work to be assessed and hold discussions with their supervisors about examiner appointments and briefing, and communicate to examiners the special value of transdisciplinary research and the journey on which it takes the researcher. Our conclusion connects these findings to the development of an emerging concept of transdisciplinary research writing.

See below under 'Recommendations for Researchers' (For the purpose of this paper, practitioners are the researchers).

The paper makes the following recommendations for transdisciplinary doctoral researchers:

- Make the data visible and argue for the unique or special way in which the data will be used

- Make clear the quality criteria against which you expect the work to be judged

- Be creative and explore the possibilities enabled by a broad interpretation of 'data'

- Transdisciplinary research is transformative. Communicate this to your examiner.

As more complex and 'wicked' problems in the world are increasingly addressed through transdisciplinary research, it is important that doctoral research in this area be encouraged, which continues to develop transdisciplinary theoretical frameworks, methodologies and applications. The strategies proposed in this paper will help to ensure the development of high quality transdisciplinary researchers and a greater understanding of the value of transdisciplinary research in the wider research community. It also draws attention to the potential benefits of similar strategies in multidisciplinary and interdisciplinary research.

Further exploration is needed of how researchers across disciplines can 'talk' to one another to resolve complex problems, and how the solitary transdisciplinary scholar, such as the doctoral student, can effectively communicate their research contribution to others. These issues could also be explored for multidisciplinary and interdisciplinary research teams. transdisciplinarity, doctorate examination, doctoral writing, data analysis, higher degree research students, research communication

\section{INTRODUCTION}

Traditional qualitative research is characterized by an effort to separate, tidy up, cut, classify, contain, clean up, and simplify data. But of course this reduces the chaotic richness of data. (Amatucci, 2013, p. 3)

Transdisciplinary research has an important role to play in addressing social, economic and environmental 'wicked problems' (Rittel \& Webber, 1973), and yet it continues to present challenges for researchers and particularly for research writing. This paper is written by four early career researchers with recent experience of completing transdisciplinary doctorates in the field of sustainable futures. We use this experience to illuminate the challenges of crafting a convincing piece of research writing 
that also makes claims of transdisciplinarity. Through analyzing the examiners' responses to our theses, and particularly those concerned with data and data analysis, we develop strategies that will assist transdisciplinary doctoral researchers in presenting their work to examiners.

Definitions and descriptions of transdisciplinary research often refer to the work of a team rather than an individual. An individual engaged in transdisciplinary research faces the challenge of meeting the criteria for transdisciplinarity within a piece of research undertaken by one person. It has been observed that early career researchers also experience professional, philosophical, methodological, and personal challenges through their engagement in transdisciplinary work (Patterson et al., 2013, p. 300) as well as particular kinds of ethical dilemmas (Palmer, Fam, Smith, \& Kilham, 2014). There has been only limited analysis of these challenges (Bracken \& Oughton, 2009, p. 371; Giacomini, 2004, p. 177), which includes a failure to recognize the significance of such research on the part of journals, promotion panels, "and even one's own agency or department" (Reich \& Reich, 2006, p. 59). Transdisciplinary doctoral students are likely to experience longer time frames for completion as they deal with supervisors from different disciplines and attempt "to bridge disciplinary intellectual and administrative silos" (Manathunga, Lant, \& Mellick, 2006, p. 368). On completion of their doctorates, they may have greater difficulty in developing a publications record, and in finding research funding and employment opportunities (Manathunga et al., 2006, p. 368).

In the authors' experience of thesis writing and examination, a particularly vexing aspect of transdisciplinary work is developing and communicating to examiners a clear understanding of 'data': what it is and how the thesis uses it convincingly. Our exploration of these issues in this paper consists of four parts: an overview of current theory on transdisciplinarity and the nature of 'data', an outline of the approach taken in each of the authors' theses, an analysis of our examiners' comments on the data and data analysis presented in our four theses, and proposed strategies for addressing the challenges of writing a transdisciplinary doctoral thesis which become evident in this analysis. We conclude with proposals for further research that could extend similar strategies into the field of multidisciplinary and interdisciplinary research.

\section{RECENT LITERATURE}

\section{WHAT IS TRANSDISCIPLINARY RESEARCH AND WHYDO IT?}

It has been argued convincingly that attempts to resolve complex 'real world' and wicked problems (Levin, Cashore, Bernstein, \& Auld, 2012; Rittel \& Webber, 1973) reveal the value of transdisciplinary approaches (Brown, Harris, \& Russell, 2010; Fam, Palmer, Riedy, \& Mitchell, 2017; Mitchell, 2009). A complex problem provides the focus for considering various contributions to knowledge and practice offered by a range of disciplines and the potential for a new solution/resolution. However, definitions of transdisciplinary research vary; some are concerned more with the theoretical and procedural challenges of crossing disciplines and others focus on practical outcomes (Mitchell, Cordell, \& Fam, 2015).

Transdisciplinarity according to Stokols (as cited in Bammer, 2012) is distinct from multidisciplinarity and interdisciplinarity:

- Multidisciplinarity is a sequential process whereby researchers in different disciplines work independently, each from his or her own discipline-specific perspective, with a goal of eventually combining efforts to address a common research problem

- Interdisciplinarity is an interactive process in which researchers work jointly, each drawing from his or her own discipline specific perspective, to address a common research problem

- Transdisciplinarity is an integrative process in which researchers work jointly to develop and use a shared conceptual framework that synthesizes and extends discipline-specific theories, 
concepts, methods, or all three to create new models and language to address a common research problem.

Others have taken the integration of disciplines further, to include types of knowledge from outside the academy, that is, from an "extended peer community, consisting of all those with a stake in the dialogue on the issue" (see also Balsiger, 2004; Funtowicz \& Ravetz, 1993, p. 739) and including those outside universities (Kirmayer, 2013, p. 367). Engaging the broader community not only gives a researcher access to different knowledges and experience, but also a better understanding of "realworld ... human reasoning and interaction" as well as social and other constraints (Horlick-Jones \& Sime, 2004, p. 452). Contributions to research can also be personal, such as experiences in a researcher's life that catalyse a "methodological turning point" in examining social or political issues (Phoenix, 2014). Brown et al. (2010) propose a collective perspective as a defining characteristic of transdisciplinarity:

'Transdisciplinary' is taken in these definitions to be the collective understanding of an issue; it is created by including the personal, the local and the strategic as well as specialized contributions to knowledge.

In this paper, we take transdisciplinary work to involve not only emergent syntheses and hybrid understandings from across disciplines, as indicated by Bammer (2012), but also engagement with community or traditional knowledges and personal experience outside the academy. A very challenging aspect of building an argument in transdisciplinary research writing is the tension between achieving a range of conclusions beyond those of disciplinary inquiry while nevertheless being judged using the same criteria that apply to discipline-based works. This tension has been acknowledged by Mitchell and Willetts (2009) who have proposed modified frameworks for examining transdisciplinary postgraduate work.

To some extent the issues described in this paper are also characteristic of issue-focused research using mixed methods that reflect diverse ontologies and epistemologies (see Nilsen \& Edwards, 2014, and other papers in the special issue of the International Journal of Social Research Methodology). Phoenix (2014) describes the ways in which sociologist Julia Brannen has responded to these issues by proposing the use of intellectual syncretism, meta-analytic thinking (about how the research and the researcher are positioned in a wider context), and a continuing commitment to policy-relevant issues from a social justice perspective (see also Moss, Mooney, O'Connell, \& Statham, 2014, p. 178). These aspects are all paralleled within the best transdisciplinary research (Fam et al., 2017). The principle distinction is that transdisciplinary research reaches across disciplines, not only methodologically but theoretically, and hence creates even deeper issues of synthesis and translation. A recent paper by Suzanne Franco (2016) traverses the issues that arise in educating doctoral students to be aware of their own epistemologies and ontologies; the work this requires is an indication of the complexities that transdisciplinary research students must address in their integration of perspectives and in communicating their research effectively to their supervisors and their examiners.

More specifically, we argue below that clarity around conceptions of 'data' is especially critical in balancing, on the one hand, the demands of engaging with a complex problem and a range of stakeholders and, on the other hand, the requirements of quality research. For the purposes of this paper, the four doctoral theses written by the authors, along with the text of our examiners' reports, become data in themselves for an examination of the challenges faced by transdisciplinary doctoral candidates (and their examiners) as these manifest themselves in each candidate's handling of his or her own data. We examine data in a transdisciplinary context by using the idea of a 'convincing' piece of research writing as defined by Golden-Biddle and Locke (1993) and take 'convincing' to entail a relationship between the researcher/writer, the 'data' and the reader (or examiner). 
Palmer, Fam, Smith, \& Kent

\section{Reflexivity}

One of the dimensions of transdisciplinary research we noted earlier is a reflexivity on the part of the researcher and an openness to new forms of knowledge. Patti Lather describes this openness as "a situated, partial, positioned, explicit tentativeness" (2001, p. 246). The 'self-conscious' research project locates the researcher, the participant 'others', the processes of interpretation and theorizing, and the project outcomes or impacts within a structure which clearly marks within it the path of the researcher as one of reflexivity, learning and transformation (Palmer, 2011, p. 77). For example, Curthoys and Docker (2010, p. 233) suggest that strongly contested histories have resulted in historians making clear to their readers their historical methods and assumptions, and "foreground[ing] the existence and normality of interpretive difference," and Portelli (2003) acknowledges that "[i]nstead of discovering sources, oral historians partly create them" (p. 72). In uncovering the new or the hitherto unexplored, researchers need to go beyond mere exclamation "framing of the world-asexhibition" (Hyndman, 2001, p. 264)), and this requires self-understanding. Unlike exclamations, drawing attention to what is "remarkable to us" entails a reflexivity about how the commentator perceives and interprets the other.

Reflexivity has been described as self-awareness of one's own cultural values (Reich \& Reich, 2006, p. 54), cultural humility (Hester, 2012), and the ability to 'hold difference and alterity' (Kirmayer, 2013, pp. 367-368). It is seen as an essential component of 'cultural competence' and of cosmopolitanism (Palmer \& Carter, 2014). Werbner (2006, pp. 497-498), for example, argues that true cosmopolitanism needs to be grounded in "elements of self-doubt and reflexive self-distantiation, an awareness of the existence and equal validity of other cultures, other values, and other mores." Similarly, the cultural competence of, for example, a health practitioner working with clients from another culture, requires a reflexive acknowledgement that the practitioner is also 'culturally embedded' (Hester, 2012, p. 286). For researchers working across cultures, as in the doctoral projects undertaken by two of the authors of this paper, Spivak (1988, pp. 274, 275) reminds us, that before 're-presenting' (describing) 'the other', researchers need to learn first to clearly represent themselves so that the cultural and ideological framing of their descriptions is not hidden in an apparently 'transparent' researcher. Reflexivity, like cultural competence, is thus an ongoing work, rather than a skill that, once acquired, is only called up as needed (Kirmayer, 2013, p. 368; Reich \& Reich, 2006, p. 54).

Alvesson (2011, p. 106) suggests, however, that these descriptions of reflexivity can lead to a focus on the 'researcher-self' and suggests instead that reflexivity is constituted by "conscious and consistent efforts to view the subject matter from different angles... Reflexivity means working with multiple interpretations in order to steer away from traps and to produce rich and varied results" (p. 107). While it could be argued that this enacted form of reflexivity would still require of the researcher the subjective qualities described above (self-awareness, humility, self-distantiation), Alvesson's form of reflexivity meets the needs of transdisciplinary research: "Jumping between paradigms is a very difficult skill, but it is not impossible to widen and vary one's horizon by looking selfcritically at favoured assumptions and lines of inquiry" (p. 108). Kirmayer (2013, pp. 367-368) and Schoot, Uiterkamp and Vlek (2007, p. 192) point out that reflecting upon one's own 'expert' position is a path to recognition and respect of other knowledges. This respect is essential in working within an interdisciplinary team (Corner \& Normand, 2001, p. 834); it also, like cultural humility, bolsters the capacity of a transdisciplinary scholar to 'jump between paradigms'.

One of the most important consequences of [the] discipline-based education system is a missed opportunity to encourage reflexive thinking about disciplinebased normative assumptions and world views (Palmer \& Carter, 2014, p. 25).

Manathunga et al (2006, p. 369, quoting Cornwell and Stoddard, 2001) liken the stages of interdisciplinary thinking to an "intercultural border crossing," where the first stage of cultural relativism or acceptance of different beliefs and practices is succeeded by "radically revaluing one's own inquiry to incorporate the questions, methods, and perspectives of others." 
Beyond reflexivity, Denzin (2013) notes that enabling researchers to work with uncertainty and experimentation calls for 'passion, and commitment' (p. 3). To this could be added "curiosity and creativity" (Fam, 2017, p. 79), which are characteristics of a transdisciplinary approach more akin to an "attitude, disposition, orientation, and/or temperament" rather than tangible, learned skills. Passion, commitment curiosity, creativity and reflexivity, combined with the complexities of data canvassed above, are factors indicating that, for doctoral students, collecting, interpreting, and writing up their data is a form of committed inquiry that might need to include their own relationship with the 'data' - the story of the researcher and the focus group, the story of the stakeholder meeting, or of the researcher's journey to the 'field'.

Before exploring the way that 'data' and 'data analysis' were used in our transdisciplinary doctoral research and interpreted by our examiners, we draw attention below to critiques of 'data' that illustrate different epistemological stances and world views.

\section{WHAT IS DATA?}

St Pierre's (2013) genealogy of data suggests that data began as the "building blocks of true knowledge that can be accumulated into regularities, generalities, scientific laws of the social world that emulate the scientific laws of the natural world" (pp. 1-2). The very term 'data' reflects, suggests Denzin (2013), a positivist epistemology and a politics of evidence associated with concepts of reliability and validity. This positivist perspective on data rejects intuitive and introspective forms of knowledge emerging from interpretations of a comment in an interview, a fragment of a field note, an anecdote, an object, or a strange facial expression (MacLure, 2013). These resist the positivist's attempt to categorize, pattern, code, or theme 'data' in a way that allows objective and generalizable conclusions to be drawn about the world.

An interpretivist research approach sees meaning and reality, including what constitutes data and how it is interpreted, as multiple and constructed within particular social, cultural, and political environments. This, however, produces concerns about the validity and trustworthiness of research conclusions. Nevertheless, qualitative researchers who attempt to 'prove' the relevance or validity of their data, for example through coding, collating, and word-counting in order to organize and thematize the data may find that the cultural richness and complexity of their data become submerged in quantitative methods: "epistemology, ontology, and methodology cease to align at that point" (St Pierre, 2013, p. 2). St Pierre suggests that interpretive theory (Marxist, feminist, or postcolonial for example) could more appropriately be used to make meaning from such data. Charmaz (2011), on the other hand, while advocating for a constructivist form of grounded theory, has argued that coding and categorizing are tools that can be used in different epistemological contexts ranging from positivist to constructivist. Alvesson (2011, pp. 6-7) points to the complexity of "interviews as data" and notes that "any meaning pulled out of interviews... is contestable"; interpreting interview texts requires "working with alternative lines of interpretation and vocabularies and reinterpreting the favoured line(s) of understanding... Perspective shifting is thus central."

Amatucci's (2013) response to concerns about the process of collecting and interpreting data is to use autoethnography as a way of answering research questions, a process she calls "data as verb". This is "writing as inquiry" and supervenes on the separate processes of collecting data and then analyzing it: "the data are the stories themselves. They come to be through the process of writing" (p. 1).

Data have also been attributed with an agency outside of methodological systems, standards, and methods: "they speak up, get rowdy, act up, resist being turned into commodities, produced by researchers, perhaps owned by the government, or by funding agencies, or by researchers" (Denzin, 2013 , p. 2). This is especially evident in data obtained through interviews, in which the voice of the informant can sometimes speak across and beyond the categories and theories to which it is assigned. In this sense, "[d]ata are generative. Data are expressive. Data are relational. Data are in active (or 
agentive) relation" (Gildersleeve \& Kuntz, 2013, p. 3). Sometimes "the data appears to absorb us and shift its form to accommodate our own teasing and worrying of it" (Benozzo, Bell, \& KoroLjungberg, 2013, p. 6). This kind of data is part of a relational engagement with the researcher; MacLure (2013) describes data as an "event", an interaction between ourselves and the world, which invites us in (p. 4). Instead of 'data', Petersen (2013, p. 5) uses the term 'creata', a term that reflects some of the diversity and unquantifiability of data in a transdisciplinary context:

... creata is generated from observation, participation in talk, events and rituals, from documents of various sorts, and self-reflection about what it means to do this kind of culture(s).

In the doctoral projects discussed here, each researcher's transdisciplinary explorations led to some engagement with this livelier, relational, culturally laden and less quantifiable form of data as well as its analysis and presentation. While the responses from examiners prove that this was a risky process, we suggest, with MacLure (2013, p. 2), that it is through such experiments that something hitherto unthought can emerge - "new connections spark among words, bodies, objects, and ideas".

However, the work of pulling together complex data with critique or synthesis of differing theoretical frameworks and world views may need to be supported by strategies that address a different (literary) level of consciousness in the reader. In discussing ethnographic or interview data, Richardson (2003, p. 190) has suggested that life stories might be better represented as short poems rather than as narratives. Ledbetter (1996) asks the researcher to pay special attention to "leaps" or discontinuities in their interviewee's narratives (p. 2); in these cases, a more 'picaresque' or fragmented narrative may be a better reflection of a traumatic or chaotic story (Ganguly, 2009, p. 439). Tools used by transdisciplinary researchers to convey complex data and its interpretation could thus include the use of a range of literary forms. Petersen (2013, p. 5) describes her "drama in three acts", taken as a whole, as data+analysis, and Gildersleeve and Kuntz (2013) describe their verbatim dialogue as inquiry + data + analysis. Some researchers take on nonhuman co-authors that have been a source of data, such as a recent paper by 'Bawaka Country et al.' (2014). Other responses include autoethnographies (Amatucci, 2013) where the writing itself becomes both data and analysis: "writing as inquiry".

\section{FOUR TRANSDISCIPLINARY THESES}

The Institute of Sustainable Futures, where the authors conducted their transdisciplinary doctorates, is guided by a mission to "create change toward sustainable futures." Sustainability - creating and maintaining "the conditions under which humans and nature can exist in productive harmony, that permit fulfilling the social, economic and other requirements of present and future generations" (Environmental Protection Agency, n.d.) - clearly encompasses complex issues and is an example of the kind of 'problem' that transdisciplinary research seems ideally suited to address (Brown et al., 2010), especially as we have defined it above.

The authors' four doctoral research projects covered a range of sustainability-related topics. While each author held slightly different interpretations of transdisciplinary research, our perspectives shared the following features:

- A focus on a particular contemporary problem or situation affecting society and the environment

- Valuing multiple perspectives and different forms of knowledge, e.g., non-expert knowledge, and bringing together frameworks from multiple disciplines

- A way of knowing and/or a way of doing designed to improve the problem or situation that is the focus of the research. Outcomes of a thesis therefore include both a contribution to knowledge and to the practices and people involved in the research problem (Mitchell et al., 2015) 
- Reflexivity and an explicit positioning of the researcher within the research process. This reflexivity involves being open to new sites for work and relational engagement, and not simply a continuous reflection on the self (Lather, 2001).

The above perspectives provide the context for this paper. Within this context, the transdisciplinary qualities of our theses were shaped by the research questions we asked and the disciplines and data we engaged with.

Palmer's (2011) thesis addressed the question, "Can the life stories of old people be a source of understanding the past that can inform planning for sustainability in the future?" and drew upon theory from trauma studies, history, adaptation/sustainability studies, social-ecological systems thinking, literary studies, cultural studies, gerontology, memory studies, subaltern studies, and geography. Fieldwork undertaken in Aceh, Indonesia (with the assistance of an interpreter) included interviews with older people in rural villages, and with local officials. Palmer developed, as part of her research, an exploratory and 'accretive' approach to transdisciplinarity that examines phenomena through multiple theoretical lenses, rather than focusing on resolution of a complex 'problem'. Primary data sources interpreted in this way included interview transcripts, notes of the author's personal experiences in the field, and other conversations with interviewees and colleagues. Interview data was coded using NVivo and themes identified using NVivo node clusters. These were then interpreted through the theoretical frameworks noted above. The findings of the research included a reconceptualization of life stories as explanatory models of vulnerability and adaptation, through their capacity to represent complexity, cumulative impacts and events prioritized according to significance for the storyteller.

In addressing the question, "How might a focus on people and practices be implicated in technological change to support the emergence of sustainable systems of sanitation?" Fam (2014) used social learning theories, innovation studies, social practice theory, and socio-technical studies as the overarching theoretical frameworks. Participatory action research and a multiple case study approach to research were adopted. The multiple case study approach was used to explore different aspects of innovation in sanitation. This approach to case study research was unconventional in that it did not seek replication through the use of multiple cases but rather to build a cumulative, synergistic understanding of innovation in sanitation. Case studies, therefore, focused on different units of analysis, and different analytical frames, methods of inquiry, and types of data (e.g., secondary and primary) throughout the research. While the area of inquiry in all case studies has remained consistent in regard to investigating innovation in sanitation, individual case studies focused on different aspects of innovation across cycles of research. The primary data sources included interview transcripts, participant observation, on-site observation, meeting notes, user feedback mechanisms, surveys, and personal journaling.

In response to the question, "How can we learn to be better at being sustainable?" Smith (2011) used development studies, ecology, thermodynamics, systems thinking, and learning theory in conjunction with participatory and action research methodologies. The first action research cycle involved development of a sustainability framework based on ecological principles. In the second action research cycle, Smith worked in Vietnam with a Vietnamese non-government organization where she applied the sustainability framework to assist with integrating the elements of an established community development program called Green Productivity for Integrated Community Development (GP-ICD). The expansion of this program into new villages experiencing challenges associated with urbanization and industrialization, such as excessive amounts of solid waste and declines in air and water quality, was made possible by a small grant acquired by the researcher. Village leaders provided feedback on their views on sustainability and the applicability of the GP-ICD program and the framework proposed by Smith to their sustainability related decisions and planning. Existing integrated approaches to development and the applicability of the proposed framework were also explored with Vietnamese and international development practitioners working in Vietnam. In the third and final action research cycle the initial theoretical framework was revised and a series of recommendations for development practice were developed in response to selected theories and the broad range of 
data collected in the second research cycle. Primary data sources included workshop notes, exercises and feedback forms, interview notes and transcripts, and participant observation

Kent's (2012) doctoral research asked, "Whether the individualization of responsibility is creating the conditions for social change on climate change?" She applied risk theory and sustainability transition theory within a social constructivist epistemology and drew on five areas of theory concerned with the role of individual agency in climate change response: political, social, psychological, philosophical, and cultural. The methodology employed a multiple case study of Australian Climate Action Groups (CAGs). Kent's primary data source was focus groups conducted with 8 CAGS over the period of 2009-2010. In addition, she drew from semi-structured interviews conducted with key environmental non-government organization informants in climate change advocacy, campaigning and direct action, and took part in the Copenhagen climate talks and actions in December 2009, two local CAG door-knocking campaigns, two Australian Climate Camps, and associated nonviolent direct actions. The resulting verbatim transcripts were thematically analyzed to form the basis of an individual case study report for each CAG. Analysis of the cases was iterative, using abductive reasoning (Blaikie, 2010). Individual case study narratives (included as an appendix to the thesis) blended the literature with the empirical data and became data in themselves.

Each of our theses was examined by three independent examiners, all but one external to our home university and, in most instances, situated outside of Australia. All four theses passed without the requirement for substantive changes or resubmission. Recommendations from the twelve examiners ranged from "no amendments", or "minor amendments" to the requirement to address criticisms "to the satisfaction of the Responsible Academic Officer" within the Institute.

'Data' - its nature and use - has been selected as a focus of discussion because, in our experience, it was the crucible in which our examiners' concerns about transdisciplinary research converged most powerfully. Examiners made a number of comments regarding the use and presentation of data that reflected a range of perspectives and were sometimes contradictory or difficult to reconcile. This is perhaps not surprising, since, as Cresswell (1998, p. 140) notes, "no consensus exists for the analysis of the forms of qualitative data."

\section{LEARNING FROM DOCTORAL EXAMINERS}

At the earliest stage of thinking about this paper, the authors identified, through extended conversations about the responses from our examiners, a common focus on data and data analysis that seemed related to the transdisciplinary nature of our theses. We then read each other's examiners' reports and, after further discussion, identified some preliminary themes, e.g., an apparent 'lack' of data and doubt about the connection between data and findings. These were tested by coding the text of the reports using NVivo, focusing on criticisms of data and analysis across all of the theses. After further discussion, the nodes identified in this coding (see Table 1) were then clustered, and a revised set of more specific themes developed. These themes emerged from a discussion about the nodes in the light of the diverse conceptions of data discussed above and agreement between us about the importance of writing 'convincingly'.

Our interpretive discussion was assisted by Golden-Biddle and Locke's (1993) paper on the 'convincing' use of ethnographic data. They define 'convincing' as consisting of three qualities:

- authenticity (conveying the informants' world to the reader)

- plausibility (enabling the reader to make sense of the informants' world)

- criticality (activating readers to re-examine assumptions) 
Table 1. Coding of text and alignment with themes

\begin{tabular}{|c|c|c|}
\hline $\begin{array}{l}\text { NODES: EXAMINERS' CRITICISMS } \\
\text { CONCERNING DATA }\end{array}$ & $\begin{array}{l}\text { NUMBER OF } \\
\text { THESES } \\
\text { WITH THIS } \\
\text { CRITICISM }\end{array}$ & THEME \\
\hline $\begin{array}{l}\text { Give the data more room to speak for itself or bring } \\
\text { the subjects to life }\end{array}$ & 2 & \multirow{4}{*}{$\begin{array}{l}\text { Presenting } \\
\text { data in a con- } \\
\text { vincing way }\end{array}$} \\
\hline Superficial use of data & 2 & \\
\hline No data & 1 & \\
\hline $\begin{array}{l}\text { Not enough data or not enough engagement in the } \\
\text { field }\end{array}$ & 2 & \\
\hline $\begin{array}{l}\text { Lack of evidence, contextualization, justification or } \\
\text { explanation of data analysis }\end{array}$ & 4 & \multirow{2}{*}{$\begin{array}{l}\text { Transparency } \\
\text { of data analy- } \\
\text { sis }\end{array}$} \\
\hline Seeking to find what you are looking for & 1 & \\
\hline Need for a stronger link between data and conclusions & 4 & \multirow{3}{*}{$\begin{array}{l}\text { Use of data to } \\
\text { build a strong } \\
\text { argument and } \\
\text { foster align- } \\
\text { ment }\end{array}$} \\
\hline Need a stronger link between theory and fieldwork & 2 & \\
\hline Assertion is not evidence & 3 & \\
\hline
\end{tabular}

We adopted this idea of 'convincing' to explore examiners' responses to our use of data because it speaks to the issues experienced by both our examiners and ourselves. The three main themes that emerged from the analysis of examiners' comments relate to (1) the presentation of data, (2) transparency of data analysis, and (3) the use of data to present a strong argument. The main nodes identified in coding the text of examiners' reports, and their alignment with themes that emerged from our discussion of these and the idea of writing convincingly, are presented in Table 1.

The analysis below has been presented in a way that avoids attribution of comments to any particular examiner. For this purpose, the authors have also been de-identified, and are referred to as Author L, Author V, etc. with letter order unrelated to the author order for this paper.

\section{THEME 1: PRESENT DATA IN AN AUTHENTIC AND TRANSPARENT WAY}

Theme 1 concerns the presentation of the data as genuine and worthwhile, which may be said to demonstrate, in Golden-Biddle and Locke's (1993) terms, "authenticity." Transdisciplinary doctoral students need to present their data to a range of disciplinary audiences with different conceptions of data. Unspoken expectations that vary between disciplines include the amount or volume of data required to make an effective argument. Somewhat contradictory comments made by examiners regarding these issues show the potential difficulty faced by a transdisciplinary doctoral student in consistently and reliably meeting these unspoken standards.

The kind of data in each of our theses varies greatly and includes both the 'raw' data (the spoken word heard 'in the field', in the focus group or the interview) and texts (a transcribed and potentially also translated version of the spoken word). Butler (2015) points out that transcription is often undertaken by someone other than the interviewee (p. 173), but that, even when the same person does both, it is possible to subsequently interpret the written transcript differently from the spoken word. Of course, in the analysis of our examiners' reports, the text of the reports is itself the 'raw' data; 
similarly, the 'raw' data of our theses could be taken to include written reflections and observational notes made by the researcher.

\section{Visibility of data}

With respect to the visibility of data, Author $\mathrm{V}$ experienced conflicting feedback from examiners. In this example, data, or more specifically the absence of data, was not a point of concern for two of the examiners (one of whom commented on the wide ranging empirical content) but the third stated that four of the six publications in Author V's thesis (submitted as a thesis by publication) contained "no data." The data in the four published publications were presented in a narrative form, which is not a valid form of representation of data across all disciplines. As a response to the examiner's comments, an additional appendix was added to the thesis with a matrix of all data sources to show the reader/examiner how these supported the conclusions of the thesis, and to enable the reader/examiners to independently draw their own conclusions. These contrasting perceptions of what counts as data reinforce St Pierre's (2013, p. 223) observation that “...data appear, come into being, exist (or not) in a particular ontological, epistemological, and methodological structure." The reader or examiners bring with them their own ontological, epistemological and methodological expectations that in turn influence the visibility of data.

The purpose of data collection in qualitative research is to study phenomena in depth, to explore their meaning and generate rich descriptions, rather than measuring or making generalizable findings. As noted earlier, rather than "building blocks ... that can be accumulated into regularities" (St Pierre, 2013, pp. 1-2), the idea of data has evolved through qualitative research to include anything from a facial expression, to a field note, to an object (MacLure, 2013). Nonetheless, in working across and beyond disciplines, transdisciplinary doctoral candidates need to make clear their assumptions about what constitutes data and to demonstrate that there is value in terms of analysis and findings in making such assumptions. Even where data and analysis appear to be clearly qualitative, as in the four theses discussed here, a transdisciplinary approach to data is likely to extend the definition of data, and the purpose of data collection, well beyond the conventions of any one discipline.

Author V was an embedded doctoral researcher. She undertook collaborative research in which she became a practitioner and was temporarily immersed in a practitioner's environment. This, suggest Wickson, Carew, and Russell (2006), reflects an understanding of the transdisciplinary researcher as one who:

...develops a deeper understanding of the problem they are investigating if they can manage to not only fuse different theoretical and lay knowledges, but also engage with the problem in context directly and experience the practice first hand as an embedded researcher. (p. 1053)

The embedded researcher has a different relationship with his or her data. Ontology and epistemology become relational (Gildersleeve \& Kuntz, 2013) and connected with those of participants, rather than absolute and fixed; the 'data' becomes a series of events and interactions of which the researcher forms an essential part. For Author V, project meeting notes, interview data, and direct observation of participants in the project became relevant sources of data for her transdisciplinary inquiry, data that were not 'available' for aggregation or the drawing of generalizable conclusions. The examiners' comments noted above suggest the complex and unspoken expectations that need to be met in making this data visible, when the transdisciplinary researcher interprets embedded experience into a written form.

\section{Adequacy of data}

In the case of Author T's thesis, examiners expressed different perspectives about the adequacy of the data. While one examiner found that the data supported the value of the conceptual frameworks used by the candidate, two others expressed reservations about the empirical basis of the work; these 
included a suggestion of inadequate sampling that might preclude generalizability of the findings and an uncritical use of field data to justify conceptual frameworks. The comments of the examiners point to perceived minimum standards for data. These standards manifest themselves in the examiners' comments concerning "what data is" and views on "how much data is enough" and how much engagement in the field of study is required. Terms such as "adequate sampling" and a more "critical use" of the data suggest a particular methodological perspective on data - one in which, as Amatucci (2013) notes, collection is followed by analysis. It contrasts with the iterative, evolving methodology typical of transdisciplinary research (Wickson et al., 2006) where the data may appear in very different forms at different stages of the research.

\section{Data and context}

Some examiners expressed a yearning for more intimacy with the data context. For example, one examiner of Author N's thesis suggested more could be said about the interview setting, especially the relationships between interviewee, interpreter, and interviewer and their likely impact on what was said. In these comments, the candidate was being asked to provide more context, to bring the informants' world alive. All the examiners of Author N's thesis sought more context and a deeper understanding of the lives of the interviewees. It seemed that the desire for intimacy with the data was motivated by the need to be given a sense of the world being investigated in the thesis as well as by an expectation of transparency and accountability within the work. It can be seen as a call to acknowledge that data live in, and are expressive of, a world outside the researcher's doctoral research (Denzin, 2013, p. 2; Gildersleeve \& Kuntz, 2013, p. 3). Richer descriptions of context are also consistent with the transdisciplinary researcher's commitment to engaging in a deep way with the 'real world'.

Yet in a transdisciplinary thesis, the desire to look more closely at the data and its context, and the requirement to incorporate and synthesize literature across multiple disciplines, creates tensions. One of Author L's examiners wanted to see more of the candidate's data directly presented within the thesis rather than the extensive analysis that drew heavily on the literature. These comments however sit in distinct contrast to those of another examiner who observed that transdisciplinarity extends beyond the provision of results and encompasses critical reflection of the data across multiple layers of meaning, evidenced in Author L's chapters of analysis and synthesis.

This begs the question, "What is of more value in a TD thesis?" Is it the presentation of the data and data analysis, or is it the critical analysis and integration across disciplines required in transdisciplinary inquiry in order to unpack deeper meanings and outcomes of the research?

\section{THEME 2: TRANSPARENCY OF DATA ANALYSIS}

The second requirement in Golden-Biddle and Locke's (1993) definition of 'convincing' is that data analysis must be 'plausible' that is, it must enable the reader to make sense of the informant's world by leading the reader from the data to an understanding of what it reveals about the world. In transdisciplinary research in particular, convincing the reader of the value of a wide array of data types (authenticity) must be followed up with a demonstrated capacity to use this array effectively to show the reader something that could not be seen from within a single discipline. In effect, what is required is to convince the reader to 'bridge the gap' between a transdisciplinary approach to data analysis and the reader's particular perspective, in a way that is meaningful to them.

Writing that bridges this gap requires a very particular skill that extends beyond a rigorous and comprehensive analysis of the data. For example, one of Author N's examiners commented that, unless the detailed coding and thematizing of transcription data was made evident in the main body of the thesis, its connection with the research findings was difficult for the reader to see. On the other hand, another of this author's examiners appeared to be satisfied with the use of the interview transcripts, noting that the author had successfully avoided using the interviewees merely as illustrations of theory. Here there are very different perceptions of what constitutes a plausible use of the data in re- 
search writing. For one reader the data was insufficiently utilized in convincing the reader of the candidate's interpretation of the world; for the other, there was an acknowledgement that the candidate had used the interview transcripts appropriately. However, both of the examiners' views indicate ways that data analysis can potentially be less than plausible, either because it is insufficiently foregrounded in the writing, or because it could be used to illustrate rather than generate conclusions.

In a similar way, one of Author L's examiners was unconvinced that a clear connection had been established between the data within the thesis, her analysis, and her theory building. Given the wideranging nature of transdisciplinary research perhaps this indicates a requirement for more transparent, specialized or bespoke data analysis processes in transdisciplinary research that can do better justice to the richness and complexity of data. Indeed, as another of Author L's examiners noted, the analysis and theory building within the candidate's thesis involved layering and connecting multiple elements (literature, empirical research, narrative, analysis, theory) in a way that may not have been immediately accessible or clear to the other examiners.

Comments from Author T's examiners further illustrate the challenge of plausibility within transdisciplinary research. One examiner called for more rigorous analysis of the field data, while another concluded that the analysis was sufficiently convincing despite comprehensive coding detail not being provided in the thesis. This comment demonstrates that a convincing piece of research writing can have flaws. However, these flaws, when all the examiners' expectations of quality research are considered on balance, must not be so great as to undermine the overall plausibility of the work.

\section{THEME 3: USING DATA TO BUILD A STRONG ARGUMENT ALIGNING THEORY, FIELDWORKAND CONCLUSIONS}

Finally, in order to be convincing, the data analysis (and what it reveals about the world) needs to be driven by, or framed within, a theoretical framework that connects it to other aspects of the world in particular, those aspects of the world that are of interest to the readers/examiners. This is the basis of the criticality that asks the readers to re-examine their assumptions about the world. It is most effective when the writing enables the reader/examiners themselves to imagine new possibilities (Golden-Biddle \& Locke, 1993, p. 613).

Transdisciplinary theses may require layers of analysis across data sets, theoretical frameworks and real world contexts that are difficult to turn into a convincing alignment within the space constraints of the thesis. Some elision may result, which can give the appearance of 'cherry picking' data to fit a preferred argument. Examiners of Author N's thesis made several comments on this aspect of 'criticality': one examiner felt that the interview transcripts could have been subjected to deeper interpretation using different, for example, Marxist, frameworks to achieve different conclusions. On the other hand, the same examiner also found that the thesis had successfully integrated a range of areas of concern, indicating that the transdisciplinary approach taken in the thesis was at least to some extent convincing in aligning theory, fieldwork and conclusions.

We note that criticality as represented here may not in itself be regarded as a sufficient achievement in a doctoral thesis. For example, two examiners of Author T's thesis were seeking conclusions that were generalizable, something that the author was not claiming for her work. She had instead selected a methodology guided by Action Research (Reason \& Bradbury, 2008), Participatory Learning in Action, and Participatory Research in Action (Chambers, 2008), the aims of which are to generate mutual and critically reflective learning and which lead to conceptual and/or practical insights from a specific context that improve human and ecological wellbeing in that context. This reflects the tension noted by Horlick-Jones and Sime (2004) between the (generalizable) outcomes often seen as valid or convincing within much discipline-based inquiry and the kind of insights and outcomes sought through transdisciplinary research. 


\section{TOWARDS A CONCEPT OF TRANSDISCIPLINARY WRITING}

Our experience of the transdisciplinary doctoral examination process and reflection on our examiners' comments has led us to believe that using a variety of sometimes unconventional data may require more than clear exposition and argumentation in order to convince. All of the authors found, on reflection, that they had to some extent addressed the special need for persuasiveness in transdisciplinary research writing by incorporating additional explanatory material into their theses for potential readers who may not previously have been involved in transdisciplinary research. Author N, for example, used much of one chapter in developing a definition of transdisciplinarity - a metatheoretical framework - in order to present the thesis as an exploration of juxtaposed phenomena rather than having a 'problem' focus. Transdisciplinary inquiry was defined as an additive process, paralleling the mixed methods approach described by Hantrais (2014) as "shedding more light on the subject... [and] drawing attention to the relative importance of different factors making up the wider picture" (p. 138).

Author V's 'thesis by publication' (i.e., consisting of papers either published or in press before the date of thesis submission) offered alternative quality criteria for assessment based on existing literature, made explicit the definition of transdisciplinarity used in the thesis and provided suggestions for examiners on how to read the thesis. Examiners were encouraged to gain an understanding of the scope of the research prior to reading the published papers, particularly by first reading the chapter on methodology and research design. This provided examiners with insight into the transdisciplinary breadth of the research before encountering the deep research in the published papers.

Author $\mathrm{L}$ introduced the idea of data within the thesis as having undergone several analytical and translational processes. For example, data obtained from focus group research had been translated into a series of case study reports (included as an Appendix to the thesis), that both described 'what happened' and contributed as rich narratives in their own right to a broader analysis of the issues.

Author $\mathrm{T}$ established the ethical and participatory criteria that guided her own personal engagement with research participants in a cross-cultural context and described the challenges this presented for data collection, analysis, and research quality and how she resolved these challenges. A definition of transdisciplinarity and the set of quality criteria which could be used to assess the entire research process were also made explicit in the thesis.

Transdisciplinary theses, however, are also likely to require a particularly skilled kind of writing in order to manifest authenticity, plausibility, and criticality. Writing a thesis that draws on several disciplines rather than one could benefit from a correspondingly wider range of literary tools and methods to "convince" (Golden-Biddle \& Locke, 1993, pp. 601-613). As noted earlier, writing genres such as poetry, fragmented narrative, and plays have been used to interpret for the reader complex ethnographic data and oral sources (Ganguly, 2009; Gildersleeve \& Kuntz, 2013; Petersen, 2013;

Richardson, 2003).

For the reflexive, transdisciplinary doctoral researcher, the process of 'writing up' research can produce its own 'creata' (Petersen, 2013) - stories of the researchers and their interactions with the 'real world' situation and with research participants. Writing these stories and representing the "chaotic richness of data" (Benozzo et al., 2013, p. 3) in a transdisciplinary context in a way that is both evocative and convincing to readers and examiners, appears likely to require the discerning use of literary methods beyond those of standard academic writing. Such writing needs to reflect the 'trans' in 'transdisciplinary' - a synthesis of data, analysis, reflection and interpretation across and beyond disciplines (Bammer, 2012). If, as discussed earlier, the researcher's transdisciplinary approach extends to working with community or traditional knowledges (Horlick-Jones \& Sime, 2004; Kirmayer, 2013), the writing may also need to speak to these sectors (Giacomini, 2004, p. 181). 
Palmer, Fam, Smith, \& Kent

\section{WAYS OF ADDRESSING DATA CHALLENGES IN TRANSDISCIPLINARY RESEARCH WRITING}

Based on the experiences described above and the diverse perspectives on data presented in the literature, we propose the following strategies for working with data convincingly when undertaking transdisciplinary doctoral research:

\section{Make the data visible and argue for the unique or special way in which the data will be used.}

Some of the comments received from our examiners reflected a sense of being provided with insufficient data or suggested that the way the data was presented was not convincing. One response to this is to add more data, as Author V did in the example above. However as can be seen from the comments of our examiners, a transdisciplinary thesis is likely to encounter diverse conceptions of data, so it is important that the nature of data for the purposes of the research be clearly defined and presented in a way that demonstrates its value in the research process. Richer contextualization of the data, as noted in the discussion of Author N's examiners' reports, can help to make clear the value of the data; drawing attention to the remoteness of the field location, the rare access gained to the participants, the unusual or special qualities of the data that make an original contribution to knowledge, all help to demonstrate value. In these and other cases, it may be important to explain how a particular kind of data can valuably inform an argument qualitatively without reference to minimum quantitative thresholds. This is particularly relevant where a transdisciplinary doctoral candidate is crossing between physical/natural science, humanities, and social science disciplines. St Pierre's (2013) genealogy of data, discussed earlier, provides a useful background for those implementing this strategy.

\section{Be creative and explore the possibilities enabled by a broad interpretation of 'data'.}

It is a privilege to engage in research, and, as we noted earlier, doing transdisciplinary doctoral research opens up the possibility of engaging with the world in unique ways (Brown et al., 2010; Fam et al., 2017; Levin et al., 2012). Applying an extended conception of data and creatively conveying this to others are important factors in supporting new ways of conceptualizing problems, generating knowledge, fostering practices to improve a real-world situation, and in communicating research. The examples shown in our discussion above suggest that the advantage conferred on the researcher in taking a transdisciplinary approach needs to be made evident to the examiners, especially where, as in the cases of Author $\mathrm{V}$ and Author L, there may appear to have been an absorption of the 'data' in the wider synthesizing narratives that are typical of transdisciplinary writing.

As noted above, adopting more creative writing techniques may help the reader both to see the data and to see the research as valuable (See Koro-Ljungberg \& MacLure, 2013 and the whole of the Special Issue overviewed earlier in this paper). Transdisciplinary doctoral students may, given the complex feat of communication this requires, find it particularly useful to seek training in creative writing or science communication skills.

\section{Make clear the quality criteria against which you expect the work to be judged.}

The examiners' critiques concerning data and data analysis which were discussed above suggest that this area is an important one in assessing the thesis. Across a diverse range of (re)presentation styles, and even where the word 'data' is barely mentioned, for each thesis there was a critical focus by examiners on data or on the use of transcripts. These criticisms sometimes reflected a lack of clarity on the part of the candidate but also a range of particular discipline-based interests in 'data' and the interpretation of source material. As most examiners in the foreseeable future are likely to be discipline-based, transdisciplinary theses are likely to continue to raise issues about fair assessment. It is therefore important for transdisciplinary doctoral candidates that a discussion takes place between them and their supervisors about the appointment and briefing of examiners. The transdisciplinary researcher themselves may choose to specify for editors, reviewers, or examiners the quality criteria 
they are aiming to satisfy. This will also assist the researcher in identifying any potential weaknesses in their research writing and in responding to examiners' comments. Building on the work done by Mitchell and Willetts (2009) on quality criteria for doctoral theses, referred to earlier, transdisciplinary doctoral candidates need to put in place specific strategies to ensure that candidate, supervisor, and examiner have a shared understanding in this regard.

\section{Transdisciplinary research is transformative. Communicate this to your examiner.}

We have noted that transdisciplinary research requires reflexivity and openness to other ways of knowing and other forms of practice (Alvesson, 2011, pp. 105-121; Manathunga et al., 2006). It also offers a space for "mutual and transformational learning... on the part of everyone involved: researchers, collaborators, and participants" (Mitchell et al., 2015, p. 92). Where examiners were clear that the thesis had made an important contribution to knowledge, as in Author T's thesis discussed above, apparent 'flaws' in data presentation or analysis become less important. Similarly, for Author $\mathrm{N}$, an absence of a Marxian analysis of the data was compensated for by the integration of insights across a number of 'areas of concern'. The power of transdisciplinary research to afford the reader such insights, through synthesizing data from a range of sources and interpreting them through theoretical frameworks from diverse disciplines, needs to be evident and celebrated in the thesis writing. In addition, given the importance of reflexivity and openness in enabling transdisciplinary research, it will be useful if the research writing also enables an examiner to accompany the student on their research journey.

\section{CONCLUSION}

As transdisciplinary approaches to research grow, so too will the need for development and communication of clear guidelines for writing transdisciplinary theses and, more generally, for transdisciplinary research writing. Thinking of the ways that data and data analysis can be 'convincing', characterized as being authentic, plausible, and critical in nature (Golden-Biddle \& Locke, 1993, pp. 599-600), provided us with a useful framework for unpicking the tensions around data as manifested in the examiners' comments on our four transdisciplinary theses. While our 'data set' was small, this unpacking has been illuminating, in part because of the high quality of the examiners' reports, for which we thank them, and in part because we have had time to reflect upon the reports. Analysis of others' examination reports would, we are sure, be equally illuminating; we are in the rare and fortunate position however of being able to collate and discuss extensively the examination reports on four doctoral theses in the relatively new, and still under-explored, area of transdisciplinary research. We have demonstrated that there are many factors at play in assessing whether data and data analysis in transdisciplinary research are, in fact, convincing. We have also used contemporary thinking on the diversity of data to suggest a number of creative ways for transdisciplinary doctoral students to present their data.

We have proposed strategies that go beyond the current literature on defining data, the nature of transdisciplinary research, and the need for reflexivity and creative research writing. The strategies we have outlined are intended to strengthen communication from candidate to examiner: by making transparent the ways in which the doctoral research defines and utilizes data, by making explicit the purpose and value of both the data and transdisciplinary approach to its interpretation/analysis, and by developing creative writing skills to transmit the excitement and transformative potential of such research to the examiner.

Transdisciplinary research is developing an important role in addressing complex and wicked problems (Fam et al., 2017), and with this comes a responsibility to be assumed by transdisciplinary doctoral researchers and those who review their work. Denzin (2013) poses some crucial reflective questions for those who work with data:

[W] ho has the power to control the definition of evidence, who defines the kinds of materials that count as evidence, who determines what methods best 
produce the best forms of evidence, whose criteria and standards are used to evaluate quality evidence? (p. 2)

These questions are foundational challenges to the way research is conceptualized, conducted, and evaluated. Finding a balance between the relative certainties and structure of disciplinary inquiry and the uncertainty and freedom of transdisciplinary inquiry will require many researchers to address such profound questions. Further exploration is needed of how researchers across disciplines can 'talk' to one another to resolve complex problems, and how the solitary transdisciplinary scholar, such as the doctoral student, can ensure that their work is, and is seen to be, a valuable contribution to knowledge. Both of these areas of need are concerned with communication and the ability of the researcher(s) to not only "hold difference and alterity" (Kirmayer, 2013, pp. 367-368) - exploring phenomena through multiple world views, epistemologies and ontologies - but also their ability to convey this process and its outcomes to each other and a wider readership. However as noted elsewhere in this paper, it is not only transdisciplinary research communication that needs further research; there is the potential for development of specialized data analysis processes or protocols for dealing with complex and diverse forms of data, so that such processes can be made transparent in transdisciplinary research.

Some of these issues are likely to be of concern not only for transdisciplinary scholarship and research projects, but also for those engaged in, for example, mixed methods research, where qualitative and quantitative methods each rely on deeper assumptions about what is measurable in the world and what constitutes a research finding. Multidisciplinary or interdisciplinary teams (Bammer, 2012) are also likely to benefit from the development of cross-disciplinary communication techniques and frameworks that enable them to understand a particular research problem from the other's perspective (see Fam \& Sofoulis, 2017, for a discussion of these issues). Research that traces the development of multidisciplinary and interdisciplinary teams as communication and shared understanding improve, may well find a form of transdisciplinarity emerging, where researchers "create new models and language to address a common research problem" (Bammer, 2012, emphasis added).

We trust that this paper, in addition to the specific strategies it proposes for transdisciplinary doctoral students, contributes to a discussion on how and where these broader reflections might begin.

\section{REFERENCES}

Alvesson, M. (2011). Interpreting interviews. London: Sage Publications. https://doi.org/10.4135/9781446268353

Amatucci, K. B. (2013). Here’s data now, happening. Cultural Studies $\leftrightarrow$ Critical Methodologies, 13(4), 342-346. https://doi.org/10.1177/1532708613487880

Balsiger, P. W. (2004). Supradisciplinary research practices: History, objectives and rationale. Futures, 36(4), 407422. https://doi.org/10.1016/i.futures.2003.10.002

Bammer, G. (2012). Strengthening interdisciplinary research: What it is, what it does, how it does it and how it is supported. Melbourne: Australian Council of Learned Academies. Retrieved from http://i2s.anu.edu.au/sites/default/files/alcoa-report/bammer 2012.pdf

Bawaka Country, Wright, S., Suchet-Pearson, S., Lloyd, K., Burarrwanga, L., Ganambarr, R., . . Maymuru, D. (2014). Working with and learning from Country: Decentring human author-ity. Cultural Geographies. https://doi.org/10.1177/1474474014539248

Benozzo, A., Bell, H., \& Koro-Ljungberg, M. (2013). Moving between nuisance, secrets, and splinters as data. Cultural Studies $\leftrightarrow$ Critical Methodologies, 13(4), 309-315. https://doi.org/10.1177/1532708613487878

Blaikie, N. (2010). Designing social research (2nd ed.). Cambridge, UK: Polity Press.

Bracken, L. J., \& Oughton, E. A. (2009). Interdisciplinarity within and beyond geography: Introduction to Special Section. Area, 41(4), 371-373. https://doi.org/10.1111/j.1475-4762.2009.00914.x

Brown, V. A., Harris, J. A., \& Russell, J. (Eds.). (2010). Tackling wicked problems: Through the transdisciplinary imagination. Oxford: Earthscan. 
Using Data Convincingly in Transdisciplinary Research

Butler, C. (2015). Making interview transcripts real: The reader's response. Work, Employment and Society, 29(1), 166-176. https://doi.org/10.1111/j.1475-4762.2009.00914.x

Chambers, R. (2008). PRA, PLA and pluralism: Practice and theory. In P. Reason \& H. Bradbury (Eds.), The SAGE handbook of action research: Participative inquiry and practice (2nd ed., pp. 297-318). London, UK \& Thousand Oaks, CA: Sage. https://doi.org/10.4135/9781848607934.n28

Charmaz, K. (2011). Grounded theory methods in social justice research. In N. K. Denzin \& Y. S. Lincoln (Eds.), The Sage handbook of qualitative research (2nd ed., pp. 359-380). London, Thousand Oaks, New Delhi: Sage Publications.

Corner, J., \& Normand, C. (2001). Working together: Crossing discipline boundaries to evaluate complex interventions. Nursing Times Research, 6(5), 829-836. https://doi.org/10.1177/136140960100600505

Cresswell, J. W. (1998). Qualitative inquiry and research design: Choosing among five traditions. London: Sage Publications.

Curthoys, A., \& Docker, J. (2010). Is history fiction? Sydney: University of New South Wales Press Ltd.

Denzin, N. K. (2013). The death of data? Cultural Studies $\leftrightarrow$ Critical Methodologies, 13(4), 353-356. https://doi.org/10.1177/1532708613487882

Environmental Protection Agency. (n.d.). What is sustainability? What is EPA doing? How can I help? Retrieved from http://www.epa.gov/sustainability/basicinfo.htm

Fam, D. (2014). People and practices: Fostering transitions toward sustainability through trandisciplinary inquiry and individual, social and organisational learning ( $\mathrm{PhD}$ thesis, University of Technology Sydney). Retrieved from https://opus.lib.uts.edu.au/research/handle/10453/24171

Fam, D. (2017). Being a transdisciplinary researcher: Skills and dispositions fostering competence in transdisciplinary research and practice. In D. Fam, J. Palmer, C. Riedy, \& C. Mitchell (Eds.), Transdisciplinary research and practice for sustainability outcomes (pp. 77-92). London: Routledge.

Fam, D., Palmer, J., Riedy, C., \& Mitchell, C. (Eds.). (2017). Transdisciplinary research and practice for sustainability outcomes. London: Routledge.

Fam, D., \& Sofoulis, Z. (2017). Trouble at the disciplinary divide: A knowledge ecologies analysis of a codesign project with native Alaskan communities. In D. Fam, J. Palmer, C. Riedy, \& C. Mitchell (Eds.), Transdisciplinary research and practice for sustainability outcomes (pp. 236-252). London: Routledge.

Franco, S. (2016). A doctoral seminar in qualitative research methods: Lessons learned. International Journal of Doctoral Studies, 11, 323-339. https://doi.org/10.28945/3564

Funtowicz, S. O., \& Ravetz, J. R. (1993). Science for the post-normal age. Futures, 25(7), 739-755. https://doi.org/10.1016/0016-3287(93)90022-L

Ganguly, D. (2009). Pain, personhood and the collective: Dalit life narratives. Asian Studies Review, 33(4), 429442. https://doi.org/10.1080/10357820903367109

Giacomini, M. (2004). Interdisciplinarity in health services research: Dreams and nightmares, maladies and remedies. Journal of Health Services Research and Policy, 9(3), 177-183. https://doi.org/10.1258/1355819041403222

Gildersleeve, R. E., \& Kuntz, A. M. (2013). Dialogue as a requiem for analysis. Cultural Studies $\leftrightarrow$ Critical Methodologies, 13(4), 263-266. https://doi.org/10.1177/1532708613487871

Golden-Biddle, K., \& Locke, K. (1993). Appealing work: An investigation of how ethnographic texts convince. Organization Science, 4(4), 595-616. https://doi.org/10.1287/orsc.4.4.595

Hantrais, L. (2014). Methodological pluralism in international comparative research. International Journal of Social Research Methodology, 17(2), 133-145. https://doi.org/10.1080/13645579.2014.892656

Hester, R. J. (2012). The promise and paradox of cultural competence. HEC Forum, 24(4), 279-291. https://doi.org/10.1007/s10730-012-9200-2 
Horlick-Jones, T., \& Sime, J. (2004). Living in the border: Knowledge, risk and transdisciplinarity. Futures, 36, 441-456. https://doi.org/10.1016/i.futures.2003.10.006

Hyndman, J. (2001). The field as here and now, not there and then. Geographical Review, 91(1-2), 262-272. https://doi.org/10.2307/3250827

Kent, J. C. (2012). Climate change - whose responsibility? From the personal to the global (PhD thesis, University of Technology Sydney). Retrieved from https://opus.lib.uts.edu.au/research/handle/10453/21796

Kirmayer, L. J. (2013). Embracing uncertainty as a path to competence: Cultural safety, empathy, and alterity in clinical training. Culture, Medicine and Psychiatry, 37, 365-372. https://doi.org/10.1007/s11013-013-9314-2

Koro-Ljungberg, M., \& MacLure, M. (2013). Provocations, re-un-visions, death, and other possibilities of "data": Guest Editors' Introduction. Cultural Studies $\leftrightarrow$ Critical Methodologies, 13(4), 219-222. https://doi.org/10.1177/1532708613487861

Lather, P. A. (2001). Validity as an incitement to discourse: Qualitative research and the crisis of legitimation. In V. Richardson (Ed.), Handbook of research on teaching (4th ed., pp. 241-250). Washington DC: American Education Research Association.

Ledbetter, M. (1996). Doing violence to the body: An ethic of reading and writing. In M. Ledbetter (Ed.), Victims and the postmodern narrative, or, doing violence to the body (pp. 1-21). Basingstoke, Hampshire: Houndsmill. https://doi.org/10.1007/978-1-349-24590-1 1

Levin, K., Cashore, B., Bernstein, S., \& Auld, G. (2012). Overcoming the tragedy of super wicked problems: Constraining our future selves to ameliorate global climate change. Policy Sciences, 45, 123-152. https://doi.org/10.1007/s11077-012-9151-0

MacLure, M. (2013). The wonder of data. Cultural Studies $\leftrightarrow$ Critical Methodologies, 13(4), 228-232. https://doi.org/10.1177/1532708613487863

Manathunga, C., Lant, P., \& Mellick, G. (2006). Imagining an interdisciplinary doctoral pedagogy. Teacbing in Higher Education, 11(3), 365-379. https://doi.org/10.1080/13562510600680954

Mitchell, C. (2009). A transdisciplinary perspective on industrial ecology research. In F. Boons \& J. HowardGrenville (Eds.), The social embeddedness of industrial ecology (pp. 152-161). Cheltenham, UK: Edward Elgar. https://doi.org/10.4337/9781848449060.00016

Mitchell, C., Cordell, D., \& Fam, D. (2015). Beginning at the end: The outcome spaces framework to guide purposive transdisciplinary research. Futures, 65, 86-96. https://doi.org/10.1016/j.futures.2014.10.007

Mitchell, C., \& Willetts, J. (2009). Quality criteria for inter-and trans-disciplinary doctoral research outcomes. Sydney, Australia: Institute for Sustainable Futures, UTS.

Moss, P., Mooney, A., O’Connell, R., \& Statham, J. (2014). Care, gender and unemployment: Changing times, changing methods. International Journal of Social Research Methodology, 17(2), 173-181.

https://doi.org/10.1080/13645579.2014.892658

Nilsen, A., \& Edwards, R. (2014). Introduction: A life in methods. International Journal of Social Research Methodology, 17(2), 93-103. https://doi.org/10.1080/13645579.2014.892654

Palmer, J. (2011). An eye open in the dark: Life story ethnography and the future of social-ecological systems ( $\mathrm{PhD}$ thesis, University of Technology Sydney, Sydney). Retrieved from https://opus.lib.uts.edu.au/handle/10453/21893

Palmer, J., \& Carter, J. (2014). Working in the border zone: Developing cultural competence in higher education for a globalized world. Knowledge Cultures, 2(4), 25-48.

Palmer, J., Fam, D., Smith, T., \& Kilham, S. (2014). Ethics in fieldwork: Reflections on the unexpected. The Qualitative Report, 19(28), 1-13.

Patterson, J. J., Lukasiewicz, A., Wallis, P. J., Rubenstein, N., Coffey, B., Gachenga, E., \& Lynch, A. J. J. (2013). Tapping fresh currents: Fostering early-career researchers in transdisciplinary water governance research. Water Alternatives, 6(2), 293-312. 
Using Data Convincingly in Transdisciplinary Research

Petersen, E. B. (2013). Cutting edge(s): An ethnographic drama in three acts. Cultural Studies $\leftrightarrow$ Critical Methodologies, 13(4), 293-298. https://doi.org/10.1177/1532708613487876

Phoenix, A. (2014). Reframing relevance: Narratives of temporality and methodological turning points in research on families and gender. International Journal of Social Research Methodology, 17(2), 105-119. https://doi.org/10.1080/13645579.2014.892655

Portelli, A. (2003). What makes oral history different. In R. Perks \& A. Thomson (Eds.), The oral history reader (pp. 63-74). London: Routledge.

Reason, P., \& Bradbury, H. (2008). Introduction. In P. Reason \& H. Bradbury (Eds.), The SAGE handbook of action research: Participative inquiry and practice (2nd ed., pp. 1-10). London, UK \& Thousand Oaks, CA: Sage. https://doi.org/10.4135/9781848607934

Reich, S. M., \& Reich, J. A. (2006). Cultural competence in interdisciplinary collaborations: A method for respecting diversity in research relationships. American Journal of Community Psychology, 38, 51-62. https://doi.org/10.1007/s10464-006-9064-1

Richardson, L. (2003). Poetic representation of interviews. In J. F. Gubrium \& J. A. Holstein (Eds.), Postmodern interviewing (pp. 187-201). Thousand Oaks, CA: Sage Publications. https://doi.org/10.4135/9781412985437.n10

Rittel, H. W. J., \& Webber, M. M. (1973). Dilemmas in a general theory of planning. Policy Sciences, 4, 155-169. https://doi.org/10.1007/BF01405730

Schoot Uiterkamp, A. J. M., \& Vlek, C. (2007). Practice and outcomes of multidisciplinary research for environmental sustainability. Journal of Social Issues, 63(1), 175-197. https://doi.org/10.1111/i.15404560.2007.00502.x

Smith, T. E. (2011). Connecting the social and ecological: An exploration of learning-oriented systemic practice in the field of 'environment and development'. (PhD, University of Technology Sydney).

Spivak, G. C. (1988). Can the Subaltern speak? In C. Nelson \& L. Grossberg (Eds.), Marxism and the interpretation of culture (pp. 271-313). Urbana, IL.: University of Illinois Press. https://doi.org/10.1007/978-1-34919059-1 20

St Pierre, E. (2013). The appearance of data. Cultural Studies $\leftrightarrow$ Critical Methodologies, 13(4), 223-227. https://doi.org/10.1177/1532708613487862

Werbner, P. (2006). Vernacular cosmopolitanism. Theory, Culture \& Society, 23(2-3), 496-498. https://doi.org/10.1177/026327640602300291

Wickson, F., Carew, A. L., \& Russell, A. W. (2006). Transdisciplinary research: characteristics, quandaries and quality. Futures, 38, 1046-1059. https://doi.org/10.1016/j.futures.2006.02.011

\section{BIOGRAPHIES}

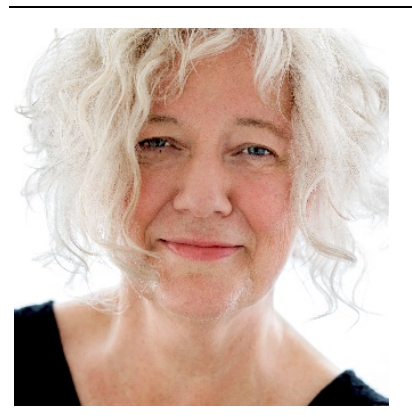

Dr Jane Palmer is a Research Fellow at the Institute for Resilient Regions, University of Southern Queensland. She has degrees in philosophy and architecture, and a doctorate from the Institute for Sustainable Futures, University of Technology Sydney. Her doctoral research was based on ethnographic fieldwork in Indonesia, and she has since been appointed to research fellowships at the University of Newcastle (Australia) and the University of Southern Queensland to undertake ethnographic projects in regional and remote Australia. Prior to her academic career, she worked for several years in northern Australia with Indigenous communities as an architect and project manager. Jane's research interests include the use of ethnographic storytelling methods to explore the processes of trauma, grief, resilience and adaptation. Her current projects are focused on supporting communities in South-West Queensland to engage with cultural heritage and explore its connection with wellbeing. 


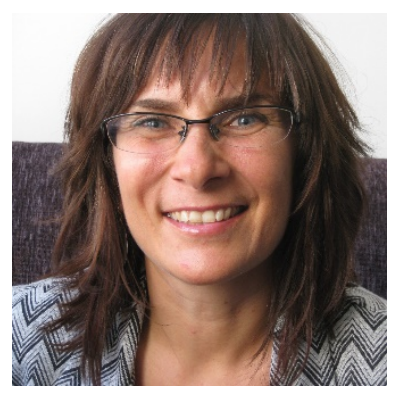

Dr Dena Fam is a systems thinker and transdisciplinary collaborator at the Institute for Sustainable Futures at the University of Technology Sydney. Over the last decade Dena has worked with industry, government and community actors to collaboratively manage, design, research and trial alternative water and sanitation systems with the aim of sustainably managing sewage and reducing its environmental impact on the water cycle. Her consulting/research experience spans socio-cultural (learning for sustainability), institutional (policy analysis), and technological aspects of environmental management. With experience in transdisciplinary project development, Dena has increasingly been involved in developing processes for teaching and learning in transdisciplinary programs and projects e.g., documenting and synthesizing processes/methods/techniques to support the development of transdisciplinary educational programs and projects. Dena has led and co-led international transdisciplinary networking events, grants and projects including an Australian-funded teaching and learning grant.

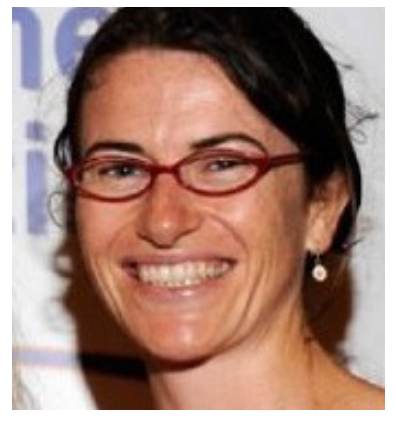

Dr Tanzi Smith's research interests include community engagement, natural resource management policy and practice and the application of systems approaches to achieve sustainable outcomes for people and the environment. She completed her transdisciplinary $\mathrm{PhD}$ at the Institute for Sustainable Futures in 2011 and undertook nine months of field-work in Vietnam as part of her doctorate. Currently she works in natural resource management in both practice and leadership roles. Tanzi holds an Honorary Associate position in the Institute for Sustainable Futures at the University of Technology Sydney. She is a Fellow of the Peter Cullen Water and Environment Trust, a past Wentworth Group of Concerned Scientists Scholar and a recipient of the Sir Edward "Weary" Dunlop Fellowship.

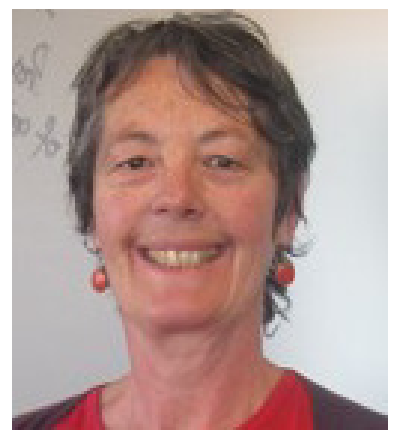

Dr Jennifer Kent is a Senior Research Consultant at the Institute for Sustainable Futures, University of Technology Sydney (UTS) as well as a sessional academic in environmental management, environmental communication and sustainability. Her research interests span the areas of sustainability transitions, grassroots social innovations and deliberative democracy. In particular, she is interested in understanding how grassroots collective voluntary action that addresses the wicked challenge of climate change and continued fossil fuel extraction can contribute to better climate change governance. She completed her transdisciplinary $\mathrm{PhD}$ in Sustainable Futures at UTS in 2012. Her research focused on how notions of responsibility for voluntary climate change action are understood and practiced at both the individual and collective level. This work formed the basis of her book, Community Action and Climate Change, published by Routledge in 2015. 